\title{
Dançar o adolescer: estudo fenomenológico com um grupo de dança de rua em uma escola ${ }^{1}$
}

\author{
Renata Marques Rego Miranda ${ }^{2}$ \\ Vera Engler Cury \\ Pontificia Universidade Católica de Campinas, Campinas-SP, Brasil
}

\begin{abstract}
Resumo: Esta pesquisa propôs-se a compreender os sentidos atribuídos à experiência de dançar por adolescentes praticantes da dança de rua no contexto de uma escola púbica de uma cidade do interior do Estado São Paulo. Trata-se de um estudo qualitativo de caráter exploratório e de inspiração fenomenológica. O referencial teórico norteador foi a psicologia de orientação humanista, especificamente a Abordagem Centrada na Pessoa (ACP), desenvolvida por Carl Rogers. A pesquisadora acompanhou, semanalmente, durante seis meses as aulas de dança e, posteriormente, realizou entrevistas individuais com sete alunos. Foram construídas sete narrativas focadas na experiência vivida pelos participantes da pesquisa sob o prisma da relação intersubjetiva estabelecida entre a pesquisadora e os alunos. Verificou-se que a experiência em foco proporcionou aos alunos a emergência de elementos típicos da experiência de adolescer, o que permitiu concluir que há uma aproximação com a proposta de aprendizagem significativa, desenvolvida por Rogers.
\end{abstract}

Palavras-chave: prevenção, fenomenologia, narrativas, dança, adolescência.

\section{Dancing and adolescence: phenomenological study of a street dancer group in a public school}

\begin{abstract}
This study aimed to understand the meanings adolescent street dancers attributed to dancing experiences within the context of a public school in the interior of São Paulo, SP, Brazil. This is a qualitative study with an exploratory approach and phenomenological background. Its guiding theoretical framework is the Humanistic Psychology, specifically the ClientCentered Approach developed by Carl Rogers. The researcher accompanied seven students weekly during six months of dancing classes and at the end of this period individually interviewed each of them. Seven narratives focused on the participants' experience were developed in the light of the inter-subjective relationship established between the researcher and the students. This experience enabled the emergency of typical elements in the adolescent street dancer group, concluding that the adolescents' experience led to significant learning, as developed by Rogers.
\end{abstract}

Keywords: prevention, phenomenology, narratives, dance, adolescent.

\section{Danzar el adolescer: estúdio fenomenológico con un grupo de baile de calle en una escuela}

Resumen: El presente estudio buscó comprender los significados atribuidos a la experiencia de la danza por adolescentes practicantes de baile de calle en el contexto de una escuela pública en una ciudad en São Paulo. Este es un estudio cualitativo, exploratorio y la inspiración es fenomenológica. El orientación teórica utilizada es la orientación humanista de la psicología, específicamente el enfoque centrado en la persona de Carl Rogers. El investigador siguió, semanalmente, por un período de seis meses las clases de baile de calle, y posteriormente se llevó a cabo entrevistas individuales con siete estudiantes. Para enfocar la experiencia de los participantes de la investigación a través del prisma de la relación intersubjetiva entre el investigador y estudiantes, se han construido siete narrativas. Este estudio mostró que la experiencia facalizada provocou lá emergencia de los elementos tipicos de la experiencia de adolescer y guarda aproximacion con la propuesta de aprendizaje significativa desarollada por Rogers.

Palabras clave: prevención, fenomenologia, narrativas, danza, adolescência.

Este artigo refere-se a uma pesquisa desenvolvida com o objetivo de compreender de forma mais estreita a interação entre a experiência de dançar e o processo de

\footnotetext{
${ }^{1}$ Apoio: CNPq. Este trabalho é derivado da Dissertação de Mestrado defendida pela primeira autora, sob a orientação da segunda, no Programa de Programa de Pós-graduação em Psicologia da Pontifícia Universidade Católica de Campinas.

${ }^{2}$ Endereço para correspondência:

Renata Marques Rego Miranda. Rua Sérgio Buarque de Holanda, 251, $1^{\circ}$ andar, Cidade Universitária Zeferino Vaz, Barão Geraldo. Campinas, SP, Brasil. CEP - 13.083-970E-mail: renatamarquesrego@yahoo.com.br
}

desenvolvimento psicológico em adolescentes, com idade entre 15 e 19 anos, inseridos no contexto de um grupo de dança de rua de uma escola pública de uma cidade do interior do Estado São Paulo.

Trata-se de um estudo qualitativo, de caráter exploratório e de inspiração fenomenológica. O referencial teórico adotado foi a psicologia humanista, especificamente a Abordagem Centrada na Pessoa (ACP), desenvolvida pelo psicólogo norte-americano, Carl Ransom Rogers (1971). O fenômeno da adolescência é compreendido aqui como parte do processo de crescimento que se desenrola a partir da tendência atualizante, e está intimamente vinculado à qualidade 
das relações humanas que são estabelecidas com pessoas significativas (Aberastury e Knobel, 1981).

O estudo insere-se na linha de pesquisa "Prevenção e Intervenção Psicológica", adotada pelos pesquisadores e alunos do Grupo de Pesquisa certificado no diretório do $\mathrm{CNPq}$ sob título "Atenção Psicológica Clínica em instituições: prevenção e intervenção". Este grupo tem se dedicado ao desenvolvimento de pesquisas de caráter etnográfico sobre enquadres clínicos diferenciados.

\section{$O$ adolescente e a dança de rua}

É em um complexo e globalizado contexto sociocultural que os adolescentes contemporâneos se desenvolvem. Os adolescentes participantes deste estudo são alunos de uma escola pública que vivem em um meio social marcado pela pluralidade, pelo consumo e, ao mesmo tempo, caracterizado pela falta de recursos, pela exclusão e pela violência.

Dança de rua, Street Dance ou Break inserem-se no movimento hip-hop como expressão de sua dança, o qual também inclui manifestações de desenho em grafite e de música pelo rap. As danças de rua tiveram origem como forma de protesto nos guetos norte-americanos e foram apreciadas e disseminadas por outros países. Alves e Dias (2004), referindo-se ao histórico do movimento hip-hop, apontam que sua origem ocorreu na década de 1960. Sua marca era a manifestação juvenil nos bairros negros e latinos de Nova Iorque. A cultura hip-hop e, especificamente a dança se configuraram como a criação de novas maneiras de ser adolescente na cidade e logo conquistaram seu espaço, expandiram-se para outros locais com outros grupos, ultrapassaram barreiras nacionais e de classes socioeconômicas.

Hoje as danças do movimento hip-hop já não são mais somente praticadas no âmbito das ruas e passaram a ser oferecidas em academias e nos palcos teatrais das cidades (Strazzacappa, 2001). Ao sair do espaço público e anônimo das ruas, as academias de dança e de ginástica resgataram os aspectos culturais do hip-hop, movimento que ficou conhecido por muitos como Street Dance em referência aos estilos e gestos rítmicos trazidos dos Estados Unidos (Alves \& Dias, 2004).

Ao refletir sobre os sentidos dos movimentos nas chamadas danças de rua, Strazzacappa (2001) considera que, apesar de apresentarem movimentação e gestos que podem ser considerados agressivos pelos adultos, as danças de rua fazem parte do universo destes adolescentes. Nestas danças e no contexto em que vivem os adolescentes alunos de escolas públicas, a violência é um tema presente e, ao dançar, é possível simular lutas, fazer gestos considerados obscenos ou indecentes, criar nas coreografias grupos que se enfrentam. Tudo isso pode ser realizado sob a forma de representação dançada e, por vezes, como um "brincar de agredir ou lutar". É interessante observar que se trata da "ritualização" da violência e não da violência em si mesma. Não é incomum grupos de dança colecionarem exemplos de adolescentes que saíram da marginalidade por encontrarem novos sentidos pessoais na prática da dança de rua. De acordo com as palavras dos próprios adolescentes, "através da dança a gente 'canaliza' nossa agressividade e, assim, não precisamos mais ser violentos com ninguém” (Strazzacappa, 2001, p. 75).

Magro (2003) considera que o hip-hop, sendo uma rede de comunicação intercultural, possibilita por meio de atitudes, linguagens e vestimentas específicas, integrar às experiências individuais questões como desemprego, violência policial, drogas, exclusão social, econômica e preconceitos de gênero. No movimento hip-hop, os signos criados e enunciados - pelo rap, por intermédio da fala; pelo grafite, por meio da imagem e pelo break, por meio do movimento - tornaram-se uma oportunidade para muitos jovens refletirem, talvez pela primeira vez, sobre questões importantes da sua comunidade e do mundo, e assim elaborarem uma reflexão crítica a respeito de suas próprias experiências, valores e posições.

\section{Método}

\section{Participantes}

Participaram desta pesquisa sete adolescentes de 15 a 19 anos, sendo cinco do gênero masculino e duas do gênero feminino, todos eles participantes do grupo de dança de rua desde a sua criação, há aproximadamente quatro anos.

\section{Considerações éticas}

O projeto de pesquisa foi aprovado pelo Comitê de Ética em Pesquisa com Seres Humanos da Pontifícia Universidade Católica de Campinas e todos os participantes foram autorizados a participar da pesquisa, mediante a assinatura do Termo de Consentimento Livre e Esclarecido pelos pais, para aqueles que eram menores de 18 anos, ou por si próprios, para os participantes que já atingiram a maioridade.

\section{Procedimentos}

\section{Coleta de dados}

Com o objetivo de compreender os sentidos atribuídos à experiência de dançar por adolescentes praticantes da dança de rua em um contexto escolar, a pesquisa desenvolveu-se em dois momentos. Inicialmente, ocorreu uma fase exploratória em que a pesquisadora realizou observação participante (André, 1997) nas aulas de dança, acompanhando de perto a experiência dos adolescentes, observando as relações interpessoais que se desenvolviam no grupo e sua dinâmica. Nesta fase os contatos da pesquisadora com o grupo de dança configuraram-se como conversas livres com o professor e com a diretora da escola, visando conhecer a dinâmica do grupo, compreender as relações interpessoais entre os profissionais e os alunos envolvidos com o projeto e facilitar a aproximação com os adolescentes. A pesquisadora acompanhou as aulas em caráter de observação participante pelo período de seis meses.

Neste período participaram do grupo aproximadamente 25 alunos. Todos foram convidados a participar das 
entrevistas individuais que constituíram o segundo momento da pesquisa. Destes 25 alunos, sete participaram das entrevistas que compuseram as narrativas.

No início de cada entrevista, com o objetivo de estimular os participantes a discorrerem sobre a própria experiência, a pesquisadora fez a seguinte questão disparadora: "Estou interessada em compreender o sentido de dançar na adolescência. Gostaria que você me contasse sobre a sua experiência com a dança". As entrevistas não foram gravadas e não seguiram um roteiro preestabelecido. A pesquisadora redigiu um texto a partir de cada uma das entrevistas e submeteu-o à apreciação dos próprios participantes, solicitando-lhes que sugerissem as alterações que julgassem necessárias.

Com base nas observações feitas durante as aulas de dança de rua e dos contatos individuais durante as entrevistas, a pesquisadora construiu sete narrativas, cujos personagens a impressionaram de maneira particular, contribuindo para a emergência da experiência em foco. As experiências narradas, ao mesmo tempo que marcam as singularidades dos seus protagonistas, contam também sobre elementos comuns aos outros adolescentes entrevistados.

\section{Análise dos dados}

Buscando coerência epistemológica entre o método utilizado para a descrição e a análise da experiência e os pressupostos fenomenológicos da psicologia humanista, foram construídas sete narrativas baseadas na relação intersubjetiva da pesquisadora com os participantes da pesquisa, a partir da proposta de Benjamin (1994) sobre a narração.

$\mathrm{O}$ método fenomenológico é adequado em pesquisas psicológicas por permitir o enfoque nos elementos subjetivos e revelá-los baseado na experiência vivida e não no que se pode pensar, ler ou dizer sobre ela (Moreira, 2004). De acordo com Campos (2008), quando o objetivo é fazer uma análise fenomenológica, é importante trazer à tona, por meio do relato, a experiência vivida. Vislumbrando este objetivo, optou-se por elaborar narrativas que incluíram a descrição, a compreensão e a interpretação do vivido, tornando presente a experiência em si mesma.

O uso das narrativas nesta dissertação foi inspirado na proposta do filósofo alemão Walter Benjamin, que dedicou parte considerável de sua obra à problemática da narração. Benjamin (1994) defendeu o uso da narrativa para possibilitar a expressão da experiência como uma forma artesanal de comunicação, contrária à idéia de expressão como mera descrição, acúmulo de informações ou lembranças acabadas em si mesmas. Para o autor, a arte de narrar está justamente em evitar explicações e permitir que contar uma história seja um acontecimento infinito e polissêmico, pois a narrativa se reconstrói continuamente á medida que é narrada.

A narrativa foi escolhida como método por possibilitar à pesquisadora afetar-se pelas histórias dos participantes da pesquisa, conforme propôs Aielllo-Vaisberg, Machado e Ambrosio (2003).

\section{Resultados e Discussão}

\section{Dançar e adolescer: narrativas de uma experiência vivida com adolescentes}

Serão apresentadas a seguir sínteses de cada uma das narrativas, combinadas com falas dos adolescentes procurando preservar a essência da experiência de dançar e de adolescer revelada pelos participantes da pesquisa. Neste artigo, dada a impossibilidade de apresentar todas as narrativas na íntegra, optou-se por não fazer apenas recortes de trechos das narrativas para não descontextualizá-las em seu fluxo de significados. Os nomes utilizados para designar os participantes são fictícios.

\section{Ed e o sentido do cotidiano}

A dança trouxe para Ed, aos 19 anos, sentido às outras tarefas do seu dia-a-dia, menos prazerosas. Mesmo sentindo-se pouco à vontade com as palavras, Ed não encontrava problemas para se expressar com o apoio da dança de rua como mais uma forma de expressão, como a definia. Sua experiência com a dança retrata a forma criativa com que vive e se organiza diariamente. Ed parece encontrar na dança o sentido para o esforço que faz:

Venho de outra cidade, entro no trabalho mais cedo para poder chegar a tempo na aula. Trabalho de garçom. Sei que nesta fase da minha vida, que trabalho quase 24 horas do meu dia, mais trabalho do que aproveito meu lazer, mas faço o possível para continuar dançando aqui.

Sua criatividade fez-se presente até mesmo em sua participação nesta pesquisa que, a princípio, não seria possível em virtude da falta de tempo. Entretanto, Ed arrumou alternativas, antecipou seu ingresso no trabalho para poder sair mais cedo e garantiu sua participação.

Ed realizava importantes trocas com o grupo de dança, pois, ao mesmo tempo que era reconhecido como o "adulto responsável" pelos adolescentes quando estes atravessavam os muros da escola para realizar apresentações na comunidade, ele, por sua vez, também contava com o apoio do grupo em sua travessia para o mundo adulto.

\section{Elis e a busca por seu estilo}

Em meio à vigilância da mãe, Elis, com 15 anos, manifestava o desejo de viver a liberdade de ser ela mesma. Pela dança ensaiou a separação ou, pelo menos, o afastamento dos pais e pôde experimentar novos vínculos importantes fora do ambiente familiar. Buscava conhecer e aproximarse da história do pai, diferenciar-se da mãe e conhecer sua história pessoal. Com a dança encontrou um meio para saber quem era, busca revelada também externamente em seu modo de vestir-se que, em suas palavras, era expressão de seu estilo Bgirl. Elis, de fora para dentro, precisou primeiramente se afirmar para o outro, para depois se reconhecer 
como diferente e única em seu "estilo" pessoal. Em suas palavras:

Tenho agora um outro estilo. Outro dia estava saindo de casa e eu tinha colocado a calça que ganhamos daqui do grupo de dança, que é bem largona, e meu pai disse: 'Essa não é a minha filha!' Eu me sinto bem assim. Essa sou eu mesma. Agora eu sou isso (fala sorrindo), o estilo do grupo de dança. Esse é o meu jeito de ser. No hip-hop tem o Bboye eu sou Bgirl. Eu gosto de me vestir assim.

\section{Fred, suas perspectivas e seus riscos}

A experiência de dançar confronta Fred com suas adversidades de vida: ser homem que gosta de dança e que dispõe de poucos recursos financeiros e apoio familiar. Aos dezessete anos, encontrou na dança prazer, perspectiva e medo do futuro. Não sentia receber dos pais o afeto que recebia do professor de dança. A expectativa que sentia que os pais depositavam nele o confundia, pois não lhe dava tempo para viver suas dúvidas e incertezas. O medo de frustrá-los somou-se aos medos do futuro. Inicialmente, Fred dançava como brincadeira e descontração. Era comum que Fred chegasse mais cedo à escola e, antes da sua aula de dança, ficasse dançando espontaneamente com os amigos. Ensaiar não define bem o que eles faziam. Fred parecia mesmo brincar de dançar antes da aula começar. As brincadeiras aconteciam livremente na forma de invenções e demonstrações de passos engraçados ou arriscados, seguidos pelo desafio aos amigos de conseguirem realizar a novidade. Pareciam divertir-se muito, pois riam, cantavam, faziam gestos e representavam. Era como dançar nas autênticas rodas de dança de rua, só que no espaço da escola.

Pouco a pouco, após conseguir uma bolsa de estudos em uma academia particular, o brincar de dançar foi sendo substituído pelo dançar como técnica, preparo profissional e expectativa de um futuro e trabalho mais gratificante.

Tenho muito medo de não conseguir, mas estou investindo. Faço algumas aulas de jazz e balé. Teve até um teste no ano passado que precisava ter experiência de hip-hop e axé. Como não entendo de axé, não prestei. Meu pai e minha mãe não se conformam com isso até hoje. Sempre falam que não acreditam que eu fico ensaiando, indo em tudo que é aula e não ganho nada por isso, e quando aparece uma chance de ganhar dinheiro com a dança, eu não vou fazer o teste! Eu tive medo de prestar, porque não entendo de axé.

Para mais além da relação com os pais, a dança traz para Fred um jeito de olhar o mundo e de se relacionar com as pessoas.
Com a dança mudei várias coisas em mim, por exemplo, eu tenho um amigo gay e não me conformava com isso, não aceitava o fato dele ser gay. Com a dança, passei a ver isso de outra forma. Se ele é gay, isso não traz nada de mal para a nossa amizade. Pelo contrário, hoje ele é um dos meus melhores amigos. Conto tudo para ele. Tudo isso que te falei sobre meus pais, sempre conversamos sobre isso. A dança ensina a gente a olhar para os outros de um jeito diferente e a aceitar mais como as pessoas são, aceitar mais os estilos de cada um.

Dançar parece facilitar o olhar-se e o olhar para o outro, promovendo um clima de aceitação interpessoal, tolerância e respeito.

\section{Klaus e seus paradoxos}

Klaus comparou a dança a uma "terapia psicológica" por sentir que lhe permitia o contato e a expressão de seus estados interiores. Aos 17 anos buscava a liberdade de ser quem realmente era, sem "bolhas" que o limitassem. A relação com o professor o apoiava em suas experiências e trazia-lhe a dimensão do futuro. O desejo de ser também um bailarino o fez buscar a perfeição do movimento e o autocontrole. Foi assim que Klaus transformou sua experiência de dançar como aproximação de si mesmo e auto-expressão em autocontrole e perfeição técnica e, paralelamente, passou a perseguir uma imagem de si coerente com as expectativas externas. Vivenciou com o professor uma relação de aceitação positiva em que parecia perceber como condição algo como: "Serei olhado e reconhecido se dançar bem". A gratidão pelo professor parece tê-lo feito crer que, caso quisesse crescer, assim como o professor esforçava-se para estar com o grupo, deveria também sacrificar algo. Klaus sentia as mudanças no grupo de dança como verdadeiros lutos adolescentes pelas perdas resultantes das transformações.

Em meio aos medos do futuro, Klaus encontrou na dança uma forma de expressar seus sentimentos:

Na dança extravaso, coloco tudo para fora. Se chego aqui triste, danço de um jeito que saio mais leve, melhor depois. Quando chego para a aula feliz, sinto que os passos saem melhores, mais limpos. A dança fica melhor. Tento não dançar com sentimentos ruins. Quando estou mal, chego na aula e antes de começar, penso um pouco, me concentro para estes sentimentos irem embora. Mas, para mim, é como uma terapia psicológica mesmo. Me faz muito bem. Quero isso para o meu futuro.

O bem-estar trazido pela dança parece trazer a Klaus a esperança de não mais sentir coisas ruins ou, pelo menos, de controlar estes sentimentos dançando. Klaus busca 
a perfeição do movimento: "Minha expressão corporal melhorou muito. Não que agora seja perfeita, mas está bem melhor". A beleza de dançar bem e de fazer os passos com perfeição contrapõe-se à possibilidade de ter a dança como forma de expressar espontaneamente os sentimentos, sejam eles agradáveis ou não de se sentir.

\section{Dora e sua criativa rebeldia}

A rebeldia de Dora para relacionar-se com outras pessoas contrastava com a disciplina, o comprometimento e a pontualidade dedicadas à dança. Aos 16 anos, vivia sua adolescência em meio a dúvidas e a dança parecia representar um apoio para a busca de si mesma, para a descoberta de como funcionava e o que gostaria de vir a ser futuramente. Dora considera que desde que começou a dançar muita coisa mudou no seu jeito de ser. "Acho principalmente que eu era rebelde por qualquer coisa. Eu era assim um pouco revoltada. Depois que comecei a dançar me sinto mais tranqüila comigo". A transformação da rebeldia de Dora em tranqüilidade parece estar relacionada com a oportunidade que encontrou, na experiência de dançar, de expressar-se e de aproximar-se dela mesma:

A dança me deu postura e com ela eu posso me expressar. Posso ficar comigo mesma e saber como estou e, se estou com raiva, triste ou brava, quando danço, eu coloco tudo isso pra fora e deixo lá. Saio melhor do que antes.

Após ler o texto com o relato de sua entrevista, acrescentou:

Dançar aqui na escola também tem me dado vontade de dar aula de dança pra outras pessoas que não teriam a chance de dançar, como eu. Até já fui falar em uma instituição carente daqui do bairro para dar aulas com o Júlio, um colega do grupo. Lá as crianças têm entre sete e onze anos. Estou com vontade de ensinar o que estou aprendendo.

\section{Tom e seu encantamento}

$\mathrm{O}$ jeito de ser de Tom não era aceito nem compreendido pelo professor, que confundia sua timidez com desinteresse. Com 16 anos, conviveu com a crítica e manteve seu interesse e organização apesar do descrédito do professor. Buscou o afeto firme e presente da amiga Dora, tão diferente dele e que, ao mesmo tempo, o aceitava como podia ser. Parecia sentir-se aceito pelas amigas e pela platéia. Experimentou o sentimento de poder pessoal:

Se posso dançar, também posso falar e fazer outras coisas bem feitas; posso aceitar críticas do professor e posso também usufruir do que os amigos e o próprio professor têm a oferecer.
Tom ganhou com a dança não só maior mobilidade corporal e beleza dos movimentos. Ganhou também autoconfiança. "Antes não tinha coragem. Na dança você tem que fazer os passos na frente de todo mundo, querendo ou não e acaba perdendo a vergonha". Ao ganhar confiança em si mesmo, Tom parece ter recuperado também a sua voz: "Já que a gente consegue dançar, às vezes passos tão complexos, com um monte de gente olhando e te julgando, então a gente também consegue falar o que pensa".

As experiências proporcionadas pela dança possibilitaram-lhe descobrir o mundo por si mesmo, em vez de recebê-lo passivamente pela televisão, como costumava fazer anteriormente. Tom dizia-se tímido e atribuía à prática da dança a sua abertura para o mundo a para as pessoas:

Para mim, dançar está sendo bom por causa da vergonha. Antes eu não estaria aqui falando com você assim sobre isso. Eu ficava mais quieto e deixava os outros falarem. Agora eu falo e fico mais (pensa) é... como vou dizer... ficou mais fácil de falar o que a gente pensa.

\section{Jorge, aquele que carrega a alma da rua}

A dança aproximou Jorge, na ocasião da pesquisa com dezoito anos, de suas origens, de sua história coletiva e individual. Buscava no hip-hop seu jeito de ser. Encontrou-o e o expressou inicialmente pelo seu modo de se vestir. Com ele, ao mesmo tempo, identificou-se e destacou-se do grupo. Dançando na escola, passou a respeitar-se e a respeitar o outro. Para expressar-se, inicialmente, desenhava, dançava, ou, ainda, apenas se aproximava sem nada falar, como fez quando pareceu estar interessado nesta pesquisa. A dança integrou suas potencialidades e trouxe equilíbrio entre corpo e mente, presente e futuro, desenho e dança, conduzindo-o a um funcionamento mais pleno. Em suas palavras, "a dança transforma (pausa), eu posso dizer isso em minha vida". Em seguida fez uma longa pausa. Jorge define-se como ex-traficante e ex-dependente químico. "A dança me ensinou como é bom ter alguém que se preocupe com você, que olhe por você, ter amigos que te escutem". Dançar parece ter devolvido a Jorge a fé em suas relações com o outro. Não qualquer outro, mas um outro que olha, ouve, respeita, acredita em seu potencial e o admira. "Eu era muito fechadão".

Referindo-se ao grupo de dança da escola, Jorge falou:

E o que eu acho de bom neste grupo é que eles têm a essência. Eles carregam a alma da rua. Eles vêm da rua. Hoje está na moda ensinar hip-hop nas academias. Não que eles não possam dançar, é claro que podem e é legal, mas falta alguma coisa que é a rua e isso eles (do grupo da escola pública) têm.

Jorge orgulha-se de pertencer a este grupo, com estas origens. Orgulha-se de ter a cultura hip-hop como sua raiz. 
Ao freqüentar a academia particular onde era bolsista, Jorge percebeu que pessoas de classes sociais mais favorecidas buscavam algo que ele naturalmente tinha, a tal da "alma da rua" e a origem na cultura hip-hop.

\section{A interlocução com outros pesquisadores na busca pelo sentido da experiência}

$\mathrm{O}$ grupo de dança de rua oferecido aos adolescentes no contexto da escola configurou-se como uma importante experiência de aprendizagem que guarda semelhanças com a descrição de Rogers (1971) sobre a aprendizagem significativa. Esta aprendizagem acontece, de acordo com o autor, na pessoa em sua integridade, pressupondo a integração de sentimentos e idéias. Inclui a aprendizagem cognitiva, que é sempre importante, e a afetivo-vivencial, esta bastante esquecida pelo ensino atual. Sentimentos como curiosidade, vibração e paixão, além de elementos vivenciais como prudência, autodisciplina, autoconfiança e emoção perante a descoberta, são parte do processo de aprendizagem significativa.

No grupo de dança estudado a aprendizagem teve um sentido pessoal, os alunos encontraram liberdade para perseguir objetivos que os tocavam individual e coletivamente, mesmo que não tivessem relação direta com a dança. Esta experiência parece ter se constituído como uma oportunidade de aprendizagem significativa uma vez que os adolescentes aprendiam enquanto encontravam espaço para experienciar os mais diversos aspectos da fenomenologia do adolescer descritos por Aberastury e Knobel (1981), como a "síndrome normal da adolescência".

As alterações corporais, tão importantes à experiência subjetiva de adolescer, puderam ser vivenciadas. De acordo com Souza (2005), o crescimento físico traz ao adolescente forças nunca antes experimentadas, além de novas capacidades e possibilidades de usar o corpo, que é agora mais potente. Aquilo que antes só era possível realizar no espaço do imaginário e das fantasias, transforma-se em possibilidades ao alcance dos jovens, o que provoca uma importante modificação na posição perante o mundo.

O corpo adolescente pôde ser vivido nas experiências com o grupo de dança de rua não apenas como corpo em luto pelo que deixou de ser na infância, mas também como um corpo adulto que nascia com o potencial de desenvolvimento e, inclusive, de procriação. A expressão da sexualidade era presente no grupo de dança tanto nas músicas e coreografias, quanto nas relações entre os adolescentes, que viviam intensas paqueras, trocas de toques corporais, olhares, elogios e críticas.

De acordo com Souza (2005), na tentativa de sentiremse reais e de encontrarem uma identidade pessoal, os adolescentes buscam formas de identificação em grupo. Não sabendo o que poderão se tornar, parecem sentir-se suspensos. As coisas e o si mesmo não lhes parecem reais. Buscam as mais variadas experiências que os façam sentirem-se reais e que, muitas vezes, trazem conseqüências à sociedade, mas que, ainda assim, não eliminam a angústia por não poderem se tornar logo aquilo que poderão vir a ser quando adultos.
Os aplausos e as entrevistas sobre o grupo de dança ao qual os adolescentes pertenciam pareciam colocá-los bem diante do próprio existir. Morato (1999) aponta que é o pertencer que oferece a possibilidade de ser quem se é, no sentido de perceber-se como consciência de si mesmo, por ser a realidade coletiva anterior à idéia que se faz de si próprio.

De acordo com Winnicott (1975), o indivíduo se constitui como pessoa sob o olhar da mãe devotada e capaz de enxergar seu bebê tal como é, e não como um feixe de suas próprias projeções. Por este motivo, considerava que uma das funções maternas essenciais para o desenvolvimento emocional do indivíduo seria a capacidade da mulher de ver seu bebê de modo a permitir-lhe ver a si próprio refletido neste olhar. Analogamente, podemos pensar que o olhar atento da platéia e dos colegas da escola, de dentro e de fora do grupo de dança, dos familiares que vinham apreciar as apresentações, do professor exigente, mas cuidadoso e presente, são exemplos de experiências nas quais os adolescentes puderam não apenas se sentirem vistos, mas, principalmente, reconhecidos em sua pessoalidade, o que, na perspectiva winnicottiana relaciona-se profundamente com a possibilidade de integração pessoal espontânea e autêntica.

Messias (2006) resume a concepção rogeriana sobre a necessidade de aceitação positiva. Com o desenvolvimento da noção de "eu", o indivíduo passa a precisar da consideração positiva de pessoas significativas. Inicialmente, é importante que os pais ofereçam aceitação positiva incondicional à criança, pois, para ela, o seu mundo são as suas experiências e a possibilidade de ser aceito incondicionalmente validará a experiência vivida. A criança que experimenta esta aceitação incondicional, pouco a pouco, vai deixando de depender dela. Passa a desenvolver um eu mais fluído e mutável que acredita nas próprias experiências, dando cada vez menor importância para avaliações externas. Este processo poderá ser facilitado pelo ambiente e será impulsionado pela tendência atualizante.

Não apenas as relações familiares são importantes para o desenvolvimento de um centro pessoal de avaliação que possibilite o abrir-se de modo congruente às experiências. Também a qualidade das relações interpessoais que se estabelecem no contexto da escola é fundamental neste processo, sobretudo na adolescência, momento em que o jovem tende a abrir-se para as relações extrafamiliares e a experimentar um interesse crescente pelo mundo que o circunda.

Com os temas em torno dos quais eram desenvolvidas as coreografias do grupo de dança, os adolescentes eram estimulados a fazerem suas pesquisas e tinham a liberdade para, em determinados momentos da aula e das coreografias, improvisarem conforme as suas criações. Foi assim que Tom se interessou pela situação da água no planeta e pelos cuidados do homem com o ambiente em que vive. Jorge interessou-se por pesquisar as danças africanas e contemporâneas. Ambos escolheram a própria direção, se auto-iniciaram e envolveram-se com o processo de forma global, tanto com seus sentimentos e paixões quanto com o intelecto. O problema 
da água no mundo que preocupava Tom, bem como as pesquisas sobre as danças africanas e o movimento hip-hop de Jorge eram problemas que tinham significado e relevância pessoais. Para um, remetia ao futuro, tão desconhecido e incontrolável. Para o outro remetia às origens e à busca por seu "estilo" individual. A própria identificação de Jorge com o movimento hip-hop formulava uma posição, expressa por uma fala, bem como por atitudes de crítica social e de busca por melhores condições de vida.

Magro (2002) considera a participação de adolescentes no movimento hip-hop uma oportunidade para explorar outros modos de ser adolescente e de torná-los protagonistas de seus próprios processos educativos não-formais, uma vez que se tornam "autores de si próprios", resgatando a educação como uma formação de "autores-cidadãos".

Para Scandiucci (2006) o hip-hop faz uma tentativa de resgate das culturas africanas e afro-brasileiras por meio do trabalho com comunidades bem como por seus ritmos e letras de suas músicas. Uma criança ou um adolescente negro-descendente, termo adotado pelo autor, que tem a oportunidade de conhecer um pouco da história de seus antepassados, como viviam na África e para que foram trazidos ao Brasil, poderá desenvolver uma percepção de si menos estigmatizada. Não é o objetivo primeiro do hip-hop aprofundar-se sobre as diferenças culturais entre as sociedades africanas, mas indiretamente recupera seus valores. Refazendo as culturas trazidas de sociedades africanas, os participantes do movimento hip-hop podem também refazer a si próprios na sociedade contemporânea, pois passam a identificar-se com algo, a pertencer a um contexto que tem raízes e passado, recuperando também um lugar no mundo.

Pertencer a um grupo pode fortalecer a auto-estima e é baseado nesta premissa que Scandiucci (2006) considera a cultura hip-hop como possibilidade de expressão e construção de uma identidade do jovem que venha a pertencer ao movimento em qualquer uma de suas manifestações, seja por meio da música, do grafite ou da dança. $\mathrm{O}$ autor, em entrevista para uma pesquisa sobre a cultura hip-hop, ouviu de um de seus participantes que se tivesse que participar de uma religião, esta seria o hip-hop. De forma semelhante, Elis definiuse de acordo com sua identificação com o hip-hop e sofreu por sentir-se impelida a escolher entre o movimento ou uma determinada religião que sentia ser imposta pelos pais.

Aberastury e Knobel (1981) descrevem a necessidade do adolescente de pertencimento grupal, esclarecendo que o grupo protege e traz a sensação de poder. Outeiral (1994) coloca que modas, costumes, atitudes e atividades recreativas têm um papel tão importante para os adolescentes, que chegam a estereotipar-se no esforço de não correrem o risco de perder o sentimento de unidade proporcionado pelo grupo. Para Elis o pertencimento ao grupo era tão importante que foi colocado lado a lado com o pertencer religioso da mãe. Foi também Elis que, dançando, aproximou-se de sua história pessoal, pois ao mesmo tempo que recuperou experiências do pai quando jovem, procurou diferenciar-se da mãe.
Outeiral (1994) considera que uma das tarefas mais importantes da adolescência é a independização, não no sentido de romper com a família, mas de transformar os vínculos infantis em um tipo de relacionamento mais maduro, independente e adulto. Este processo é doloroso para ambas as partes e sofrerá influência pela forma como os pais também vivenciaram suas transformações com os avós dos adolescentes. Poderá ocorrer de os adolescentes desvalorizarem os pais na tentativa de afastá-los e, com isso, progredirem em sua busca pela independência. A necessidade de separação dos pais os aproxima do grupo.

Ao refletir sobre o trabalho em educação com adolescentes, Rogers (1971) questionou-se sobre o quanto os estudantes realmente são colocados em um clima de confiança e facilitador da autodireção. Questionou-se também sobre o que se faz com as ambivalências despertadas por estes difíceis questionamentos. Na concepção de Aberastury e Knobel (1981), o mundo dos adultos tem dificuldade para aceitar as flutuações imprevistas do adolescente sem mobilizar-se, por reeditarem nos adultos algumas das ansiedades básicas que estavam resguardadas até então.

Aprendizagens significativas, ao conduzirem à aproximação e ao contato com a experiência, promovem orientações de valores comuns aos indivíduos e talvez, até mesmo, às culturas. Valores como sinceridade, independência, autodireção, autoconhecimento, respeito, receptividade social, responsabilidade social e relacionamentos amorosos interpessoais emergem e desenvolvem-se pela abertura à própria experiência e levam os indivíduos a engrandecerem a si mesmos e aos outros (Rogers, 1971).

Certa vez, o grupo de dança dirigiu-se para um local de apresentação e quando lá chegaram perceberam que não haviam levado o Compact Disc (CD) com a música da coreografia que apresentariam. Como o professor não os acompanhava em todas as apresentações, nesta ocasião precisaram arcar com as conseqüências do esquecimento: voltaram para a escola sem apresentarem-se. Possivelmente esta experiência contribuiu para o reconhecimento e aceitação dos alunos, conforme propõe Rogers (1983), de sua responsabilidade, substituindo a disciplina externa pela autodisciplina.

Ribeiro e Andrade (2006), em estudo sobre a assimetria na relação entre família e escola pública, referem que a maior parte dos problemas enfrentados com os alunos é justificado pela escola como responsabilidade ou do próprio aluno ou da sua família. O grupo de dança pesquisado abre uma oportunidade para uma educação fora da sala de aula e ainda dentro da escola que compartilha responsabilidades, trazendo para a própria escola a difícil tarefa de uma educação para a autonomia, além de oferecer a oportunidade de interação com a comunidade nas apresentações do grupo e com a família dos alunos.

Rogers (1983) pondera que a responsabilidade por si mesmo é tão assustadora para alguns estudantes quanto o é para os facilitadores dar-lhes esta oportunidade. Acontece de muitos adolescentes que reivindicam mais liberdade, ficarem 
confusos e até paralisados quando se vêem diante da possibilidade de viverem uma liberdade responsável. Exemplo é a atitude de determinados adolescentes que nas atividades de improvisação pareciam perdidos e confusos com tamanha liberdade sobre como se movimentar e o que fazer consigo mesmos.

A travessia ao mundo adulto permeou a experiência dos adolescentes com a dança. Assim como Dora declarou, os adolescentes ainda não estavam certos quanto ao que queriam para seu futuro e, enquanto viviam suas dúvidas, apoiavamse na dança. Dançavam enquanto adolesciam e adolesciam enquanto dançavam. Na perspectiva de Winnicott (1975), a única "cura" possível para o adolescente e para a sua essencial imaturidade é a passagem do tempo, enquanto vive uma época de descoberta pessoal engajado em sua própria experiência.

Alguns adolescentes do grupo trabalhavam ou faziam "bicos" para ganhar o próprio dinheiro ou ajudar a sustentar a família. Outros dedicavam-se a diferentes atividades além da escola, como, por exemplo, a participação em grupos de dança como bolsistas. Em meio a rotinas atarefadas e, para alguns, já bastante semelhantes à rotina de um adulto, as aulas de dança oportunizavam a brincadeira, a descontração e o lúdico. No grupo da escola pública, brincavam de dançar uma dança que encena a dura realidade das ruas, porém com a proteção dos muros da escola.

Alguns dos adolescentes chegam a mencionar a dança como perspectiva de profissão, outros a colocam na posição de uma atividade paralela ao trabalho e à família como uma condição necessária ao bem-estar e a uma vida adulta equilibrada. Para mais além dos projetos de tornarem-se adultos que praticam dança, estes adolescentes parecem estar falando sobre a perspectiva de um futuro em que haja espaço para o prazer e para os cuidados consigo mesmos, aspectos que encontraram na dança durante a adolescência. De acordo com Winnicott (1975), o brincar da criança pequena se propaga num brincar mais amplo, concretizado pelas artes ou pela religião, por exemplo. Neste sentido, o dançar constituiu-se um brincar mais amplo para os adolescentes que agora desejavam levá-lo para o mundo adulto.

A frase "eu quero dançar sempre" ou "para sempre" presente em alguns dos relatos dos adolescentes parecia um esforço de buscar alguma segurança para o incerto e nebuloso futuro. Gostariam que a dança, ou melhor, o prazer e a segurança que encontravam dançando no grupo da escola pública os acompanhassem em seu futuro. Dançar no futuro parecia confortá-los face aos medos do mundo adulto. Entretanto, Klaus, que escolheu dançar como profissão e já fazia esforços para tornar este projeto realidade, lidava com o ônus de sua escolha.

A pesquisa de Barros, Coscarelli, Coutinho e Fonseca (2002) que trata sobre o uso que os adolescentes fazem de seu tempo livre, isto é, fora das salas de aula, revela, com relação às atividades culturais, que parte considerável dos entrevistados vai ao cinema e a shows de música, indicando uma motivação dos adolescentes para participarem de atividades culturais, ao contrário do que freqüentemente se acredita.

Para Souza (2005), a família e outras estruturas sociais têm grande importância para o adolescente por oferecerem continência ante as turbulências do crescimento emocional. Outeiral (1994) considera a noção de limites, em geral compreendida de forma negativa e relacionada à repressão, proibição e interdição, como algo além disso, que indica para a criação de um espaço protegido para que o adolescente explore a sua espontaneidade e criatividade sem medo e riscos, estando a criatividade na adolescência diretamente relacionada com a noção de limites. O autor lembra que não há nenhuma espécie de conteúdo que seja capaz de organizar-se sem a existência de um continente para lhe dar forma. Não oferecer ao adolescente limites o impede de exercer a sua capacidade de pensar, ser criativo e espontâneo, pois tanto crianças quanto adolescentes necessitam e pedem limites que os ajudam a organizarem-se. Pode acontecer de os adultos absterem-se de colocar limites aos adolescentes, uma vez que para isso é necessário envolverem-se de modo que os contenham, suportando suas reclamações e protestos, processo que não é fácil.

A escola, de acordo com Outeiral (1994), é como uma "simulação da vida", com regras para serem seguidas e também transgredidas. Ao transgredir, o aluno lidará com as conseqüências da escola, que ainda são mais amenas do que as conseqüências impostas pela sociedade. A escola oportuniza $\mathrm{o}$ aprendizado com a transgressão. $\mathrm{O}$ adolescente encontra na escola uma microssociedade, com um sistema de forças, regras e valores que o impactam e onde pode competir, dividir, rivalizar, oprimir e ser oprimido, assim como o é no sistema social real, experiências essenciais para quem está buscando continuamente a si mesmo. É por esta razão que Outeiral (1994) considera que a escola está numa posição privilegiada na promoção do crescimento do aluno, uma vez que este aparece por inteiro na busca de si mesmo e a escola pode oferecer um olhar atento sobre quem ele é.

A dança de rua traz em si um aspecto transgressor por encenar a realidade das ruas marcada por violência e falta de recursos. Porém, dançar a dança de rua na escola tem um gosto especial de "transgressão segura". A escola ofereceu a proteção que as ruas e o mundo adulto não teriam condições de oferecer.

As instituições como as escolas são cenários privilegiados que viabilizam, por meio de diferentes práticas culturais e esportivas, o aprendizado de formas de ser e de estar no mundo. Ao mesmo tempo, estes contextos configuram-se como cenários capazes de atribuir novos sentidos às transgressões e aos desejos dos adolescentes. Experiências esportivas e culturais têm o potencial de concretizar o desejo de transgredir e pertencer, por serem reconhecidas pelos adultos nos âmbitos familiar e escolar, como protegidas e saudáveis (Molina, Silva, \& Silveira, 2004, p.134). 
Aun, Morato, Noguchi e Nunes (2006), em estudo sobre transgressão e juventude encarcerada, propõem compreender o transgredir como a exploração de limites internos e externos, particulares e coletivos, de modo que o sujeito que transgride transcende o familiar onde habita e é reconhecido por si próprio e pelos outros. Nesta perspectiva, a transgressão é considerada uma maneira de conhecer limites e possibilidades de si mesmo, do outro e do mundo. A combinação entre contexto escolar e dança de rua parece ter dado contorno às buscas de transgressão e de pertencimento de alguns dos adolescentes.

A pesquisadora pensa que a experiência de dançar a dança de rua no contexto da escola proporcionou a ampliação da autonomia e da autoconfiança dos adolescentes. Finalmente, a experiência de dançar na escola, não se dirige à busca de mudanças no padrão de comportamento que resultem em jovens mais disciplinados, "bem-comportados" e aptos a absorver uma vasta bagagem teórica. Busca-se sim a retomada também no espaço escolar da autonomia pessoal como medida de prevenção e promoção de um desenvolvimento psicológico saudável.

A educação de adolescentes requer suporte por parte dos adultos às suas flutuações, além da colocação de limites que permitam a transgressão e o pertencer e, paralelamente, abram espaço para a autodireção e a auto-avaliação.

\section{Considerações finais}

Esta pesquisa contribuiu para a constatação da necessidade de cuidar da escola como um espaço potencial de crescimento pessoal e de desenvolvimento humano. É na escola que as crianças e os adolescentes passam considerável parte de seus dias, de modo que a educação para a vida, e não apenas para o aprendizado de conteúdos importantes ao vestibular, acontece hoje mais no espaço escolar do que no familiar. Espaço escolar está sendo usado aqui de forma ampliada e não se refere apenas às situações de sala de aula, mas ao tempo que se passa na escola e à qualidade das relações humanas estabelecidas dentro dela.

Dançar no grupo da escola trouxe novas e criativas formas de viver o adolescer, entendendo-se criatividade como uma aproximação significativa do viver, conforme propõe Winnicott (1975) e acrescenta Ab'saber (2005, p. 77): “(...) o ato criativo traz, já na origem o que é específico do humano, a imantação para si mesmo do self criador, que encontra o que já estava lá para ser encontrado, o humano no mundo humano". Em toda a experiência narrada, a tendência atualizante atuou como guia para a abertura às experiências de dançar e de adolescer. Mediante as inevitáveis adversidades de vida, a tendência atualizante dirigiu-se em favor da busca de ser quem se é.

\section{Referências}

Aberastury, A., \& Knobel, M. (1981). Adolescência normal (S. M. G Ballve, Trad.). Porto Alegre: Artes Médicas.
Ab'saber, T. A. M. (2005). A criatividade de Winnicott. Memória da Psicanálise, Vol. 5. São Paulo: Ediouro.

Tales, A. M. (2003). A alma, o olho e a mão: Estratégias metodológicas de pesquisa na Psicologia Clínica Social Winnicottiana. In T. M. J. Aiello-Vaisberg, M. C. L. Machado, \& F. F. Ambrosio (Orgs.), Trajetos do sofrimento humano: Desenraizamento e exclusão (pp. 6-16). São Paulo: Cadernos Ser e Fazer.

Alves, F. S., \& Dias, R. (2004). A dança break: Corpos e sentidos em movimento no hip-hop. Motriz,10(1), 01-07.

André, M. E. D. A. de. (1997). Tendências atuais da pesquisa na escola. Cadernos CEDES, 43, 46-47.

Aun, H. A., Morato, H. T. P., Noguchi, N. F. C., \& Nunes, A. P. (2006). Transgressão e juventude encarcerada: Outras versões a partir do plantão psicológico em unidades de internação da FEBEM/SP. Imaginário, 12(12), 35-53.

Barros, R., Coscarelli, P., Coutinho, M. F. G., \& Fonseca, A. F. (2002). O uso do tempo livre por adolescentes em uma comunidade metropolitana no Brasil [Versão eletrônica]. Adolescência Latinoamericana, 3(2). Retirado em 10/03/2008, de http://ral-adolec.bvs.br/ scielo.php?script=sci_arttext\&pid=S1414713020020002 00008\&lng=es\&nrm $=$ iso

Benjamin, W. (1994). O narrador: Considerações sobre a obra de Nikolai Leskov. In W. Benjamin, Magia e técnica, arte e política: Ensaios sobre literatura e história da cultura (p. 200) (S. P. Rouanet, Trad.). São Paulo: Brasiliense.

Campos, A. P. S. (2008). Atenção psicológica clínica: Encontros terapêuticos com crianças em uma creche. Dissertação de mestrado não publicada, Pontifícia Universidade Católica de Campinas, Campinas, SP.

Magro, V. M. M. (2002). Adolescentes como autores de si próprios: Cotidiano, educação e o hip-hop. Cadernos CEDES, 22, 63-75.

Magro, V. M. M. (2003). Meninas do graffiti: Educação, adolescência, identidade e gênero nas culturas juvenis contemporâneas. Tese de doutorado não publicada, Universidade Estadual de Campinas, Faculdade de Educação, Campinas, SP.

Messias, T. S. C. (2006). Compreensão psicológica das vivências de pais em aconselhamento genético $(A G)$. Tese de doutorado não publicada, Pontifícia Universidade Católica de Campinas, Campinas, SP.

Molina, R. M. K., Silva, L. O., \& Silveira, F. V. (2004). Celebração e transgressão: A representação do esporte na adolescência. Revista Brasileira de Educação Física e Esporte, 18, 125-36.

Morato, H. T. P. (1999). Serviço de aconselhamento psicológico do IP - USP: Aprendizagem significativa em ação. In H. T. P. Morato (Org.), Aconselhamento psicológico centrado na pessoa: Novos desafios (pp. 2744). São Paulo: Casa do Psicólogo.

Moreira, D. A. (2004). O método fenomenológico na pesquisa. São Paulo: Pioneira Tompson.

Outeiral, J. O. (1994). Adolescer: Estudos sobre adolescência. Porto Alegre: Artes Médicas. 
Ribeiro, D. F., \& Andrade, A. S. (2006). A assimetria na relação entre família e escola pública. Paidéia (Ribeirão Preto), 35, 385-394.

Rogers, C. R. (1971). Liberdade para aprender. (E. Machado \& M. P. D. Andrade, Trad.). Belo Horizonte: Interlivros.

Rogers, C. R. (1983). Um jeito de ser. (M. J. C. Ferreira \& A. Lamparelli, Trad.). São Paulo: EDUSP/EPU.

Scandiucci, G. (2006). Cultura hip-hop: Um lugar psíquico para a juventude negro-descendente das periferias de São Paulo. Imaginário, 12(12), 225-249.

Souza, R. C. (2005). Adolescência: Tempo de enfrentamento (Viver Mente \& Cérebro: (Coleção Memória da Psicanálise. D. W. Winnicott, Vol. 5.). São Paulo: Ediouro.

Strazzacappa, M. (2001). A educação e a fábrica de corpos: Dança na escola. Cadernos CEDES, 53, 69-83.

Winnicott, D. W. (1975). O brincar e a realidade. J. O. A. Abreu, \& V. Nobre, Trads. Rio de Janeiro: Imago. (Original publicado em 1971)

Renata Marques Rego Miranda é Mestre em Psicologia como Profissão e Ciência pelo Programa de Pós-graduação em Psicologia da Pontifícia Universidade Católica de Campinas (PUCCAMP). Psicóloga Clínica do Serviço de Assistência Psicológica e Psiquiátrica ao Estudante da Universidade Estadual de Campinas.

Vera Engler Cury é Pró-Reitora de Pesquisa e Pós-graduação da Pontifícia Universidade Católica de Campinas (PUCCAMP). Professora Doutora Permanente do Programa de Pós-graduação em Psicologia e Professora Titular da Faculdade de Psicologia da PUCCAMP.

Recebido: 19/11/2008

$1^{a}$ revisão: $25 / 07 / 2009$

Aceite final: 10/08/2009 